Global Conferences Series:

Sciences and Technology (GCSST), Volume 5, 2020

Seminar Nasional I Baristand Industri Padang (Semnas I BIPD)

DOI:https://doi.org/10.32698/GCS-SNIIBIPD3438

\title{
Evaluation of the solid soap quality from catechins
}

\section{Evaluasi mutu sabun padat dari katekin}

\author{
Dwi Mulyani $^{1}$, Gustri Yeni ${ }^{2}$, Devahimer Harsep Rosi ${ }^{1}$ \\ ${ }^{1}$ Akademi Farmasi Imam Bonjol, Bukittinggi, Indonesia \\ ${ }^{2}$ Balai Riset dan Standardisasi Industri Padang, Indonesia \\ E-Mail : Dwimulyani.Mul21@Gmail.Com
}

\begin{abstract}
Uncaria gambir Roxb contains catechins which are the main component, has a high economic value so it is a good prospect for farmers, has astringent, antibacterial, and antioxidant characteristics. The catechins in Uncaria gambir Roxb have several functions for skin health, such as rejuvenating the skin which is able to maintain skin strength and elasticity and keep skin youthful. This study was aimed to obtaine a good formula for solid soap. The Solid soap is formulated by adding NaOH, Aquadest, olive oil, coconut oil, and $V C O$ oil. All formulas meet the physical evaluation requirements, are solid form, light brown in color, and have a distinctive aroma of catechins. Foam height in Formula 1 (F1): 1.6-5.2cm; Formula 2 (F2): 2.3-4 cm; and formula 3 (F3): 2.1-4 cm. Water content F1: 14.94\%; F2: 12,82; and F3: 14,6. Check pH F1: 9; F2: 10; and F3: 9. All formulas are non-irritating to skin.
\end{abstract}

Keywords: solid soap; catechi; Uncaria gambir Roxb

\begin{abstract}
Abstrak: Uncaria gambir Roxb mengandung katekin yang merupakan komponen utamanya, memiliki nilai ekonomi tinggi sehingga memiliki prospek yang baik bagi petani, memiliki daya astringensia, antibakteri, dan antioksidan. Katekin dalam gambir mempunyai beberapa fungsi bagi kesehatan kulit, seperti meremajakan kulit yang mampu mempertahankan kekuatan dan elastisitas kulit serta membuat kulit awet muda. Penelitian ini bertujuan untuk mendapatkan formula yang baik dari sabun padat dengan zat khasiat utama katekin. Sabun padat diformulasikan dengan penambahan $\mathrm{NaOH}$, Aquades, dan minyak yaitu minyak zaitun, minyak kelapa dan minyak VCO. Semua formula memenuhi persyaratan evaluasi fisik, bentuk padat, warna krem, dan aroma khas katekin. Tinggi busa Formula 1(F1) : 1,6-5,2 cm ; Formula 2 (F2): 2,3-4 cm ; dan formula 3 (F3) : 2,1-4 cm. Kadar air F1:14,94\% ; F2:12,82 dan F3:14,6. Pemeriksaan pH F1:9 ; F2:10 dan F3:9. Semua formula tidak mengiritasi kulit. Hasil evaluasi sabun padat katekin yang diformulasikan F1,F2 dan F3 semuanya baik (memenuhi standar evaluasi mutu sabun padat).
\end{abstract}

Kata kunci: sabun padat; katekin; Uncaria gambir Roxb

\section{PENDAHULUAN}

Indonesia merupakan negara pengekspor gambir terbesar di dunia. Ekspor gambir Indonesia tahun 2018 tercatat sebesar 18.000 ton dengan nilai ekspor mencapai USD 55 juta (Ditjen Pekebunan, 2019). Senyawa polifenol utama yang terdapat pada ekstrak gambir ini adalah katekin yang berperan sebagai senyawa antimikroba dan antioksidan (Aditya dan Putri, 2016). Katekin juga memiliki aktivitas fotoproteksi terhadap UV-A dan UV-B (Setyowati, 2017).

Saat ini, produk kosmetik sudah menjadi kebutuhan primer bagi kaum wanita yang merupakan target utama dari industri kosmetik. Seiring dengan perkembangan zaman, industri kosmetik juga mulai berinovasi pada produk kosmetik untuk pria dan anak-anak. Tren masyarakat mulai memperhatikan produk perawatan tubuh sebagai kebutuhan utama dan penggunaan produk alami (back to nature), membuka peluang munculnya produk kosmetik berbahan alami (Kemenperind, 2018).

Copyright (C) 2020, the Authors. Published by Redwhite Press. 
Siguntur Kabupaten Pesisir Selatan juga penghasil gambir dari Sumatera barat. Kultivar gambir Siguntur menunjukkan aktivitas antioksidan dengan sifat antioksidan yang sangat baik, yang mampu untuk membasmi radikal bebas. Aktivitas perendaman radikal DPPH berkisar antara 92,0 hingga 93,1\% dan kandungan katekin berkisar antara 99,4 hingga 108,5 $\mu \mathrm{g} / \mathrm{ml}$. Katekin diidentifikasi sebagai senyawa bioaktif utama dalam gambir Siguntur (Anggraini et al., 2011).

Penelitian isolasi katekin dari gambir untuk sediaan farmasi dan kosmetik diketahui bahwa metode terbaik isolasi katekin untuk bahan baku obat dan kosmetik adalah pre purifikasi (ekstraksi berulang dengan air dan etil asetat) dengan kadar katekin 96,17\% - 97,82 \% (Rahmawati, 2012 ; Yeni et al, 2019). Katekin berkhasiat sebagai antioksidan guna meremajakan kulit yang mampu mempertahankan keteguhan dan elastisitas kulit serta menjaga keadaan kulit awet muda (Neswati et al., 2019).

Pada masa pandemi covid 19 ini, produksi sabun fungsional berbahan alami perlu digunakan, seperti katekin yang merupakan salah satu senyawa bioaktif yang terkandung dalam gambir.Sabun adalah senyawa natrium atau kalium dengan asam lemak dari minyak nabati atau hewani yang berbentuk padat, lunak atau cair, berbusa digunakan sebagai pembersih, dengan menambahkan zat pewangi, dan bahan lainnya yang tidak membahayakan kesehatan (SNI, 1994). Sabun merupakan salah satu produk kosmetikuntuk perawatan tubuh yang dibutuhkan oleh semua lapisan masyarakat. Terutama sabun yang berkhasiat anti aging dan anti mikroba.

Penelitian ini bertujuan untuk mendapatkan sabun padat dari katekin yang memenuhi syarat evaluasi mutu sabun padat. Sabun katekin dapat meningkatkan pemanfaatan tanaman lokal, menjawab kebutuhan masyarakat akan perawatan tubuh saat ini, termasuk kebutuhan produksi nasional yang banyak dilirik oleh wisatawan luar negri.

Sabun padat umumnya banyak digunakan untuk sabun mandi. Komposisi sabun biasanya mengandung surfaktan, pelumas, antioksidan, deodoran, warna, parfum, pengontrol $\mathrm{pH}$, dan bahan tambahan khusus. Surfaktan adalah lemak dan minyak yang dipakai dalam sabun berasal dari minyak kelapa, minyak zaitun, atau lemak babi. Untuk menghindari rasa kering pada kulit diperlukan bahan yang dapat melembabkan dan berfungsi untuk membentuk sabun yang lunakmisalnya, asam lemak bebas, gliserol,lanolin,parafin lunak, cacao, sebagai pelumas. Pewarna sabun boleh digunakan memenuhi syarat dan peraturan yang ada, pigmen yang digunakan biasanya stabil dan konsentrasi kecil (0,01-0,5\%). Komponen lain pada sabun adalah parfum yang berfungsi sebagai pewangi. Setiap pabrik memiliki bau dan warna sabun tergantung pada permintaan pasar atau masyarakat pemakainya. Penambahan asam lemak yang lemah, misalnya asam stearat, dapat menurunkan $\mathrm{pH}$ sabun, digunakan sebagai pengontrol $\mathrm{pH}$ (Wasitaatmadja, 1997).

\section{METODE}

\section{Alat dan Bahan}

Alat yang digunakan adalah, timbangan, botol gelap, corong, rotary evaporator, pipet tetes, gelas ukur, erlenmeyer, oven, Mixer, dan $\mathrm{pH}$ meter. Bahan yang digunakan adalah gambir, etil asetat, aquadest, minyak zaitun, minyak kelapa, $\mathrm{VCO}$, dan $\mathrm{NaOH}$.

\section{Pelaksanaan Penelitian}

Penelitian formulasi sabun ini menggunakan ekstrak katekin dari gambir. Serbuk gambir $1 \mathrm{~kg}$ dimasukkan ke dalam erlenmeyer 2 L tambahkan air sebanyak 5 L, panaskan selama 1 jam lalu disaring. Filtrat didiamkan sampai terbentuk endapan. Endapan dikeringkan dalam oven kemudian diserbukkan dan ditambah etil asetat lalu direfluks selama 1 jam dan disaring. Filtratnya dikentalkan menggunakan rotary evaporator, dikeringkan dan dianalisa. Pengulangan dilakukan sebanyak 3 kali. Sabun padat katekin dibuat dalam 3 jenis formula dengan penambahan 3 jenis minyak dan variasi konsentrasi dari katekin.

Formula menggunakan katekin 10 gram (F1), 15 gram (F2) dan 25 gram (F3). Kedalam formula ditambahkan masing-masingnya minyak zaitun $235 \mathrm{~g}$, minyak kelapa $150 \mathrm{~g}$, VCO $100 \mathrm{~g}, \mathrm{NaOH} 74 \mathrm{~g}$, dan aquadest 210 g. Sabun mandi padat dibuat mengacu pada penelitian Latifah Rabani tahun 2019 yang dimodifikasi, dengan cara sbb: semua minyak, dicampur masukkan kedalam wadah, lalu dimixer selama 5 menit. Lalu katekin larutkan dalam beaker glass dengan aquadest panas (1:1) (Yeni,dkk, 2017), dimasukkan kedalam campuran yang sudah dimixer tadi. Tambahkan $\mathrm{NaOH} 74 \mathrm{~g}$ dilarutkan ke dalam sisa aquadest dalam beaker glass $250 \mathrm{ml}$. Larutan $\mathrm{NaOH}$ tersebut akan panas dan berwarna keputihan, selanjutnya dinginkan dalam suhu ruang. Larutan $\mathrm{NaOH}$ yang telah dingin dimasukkan ke dalam campuran mixer, kemudian di mixer hingga mengental dalam waktu 15 menit. Adonan yang sudah terbentuk di masukkan ke dalam cetakan selama 3 hari. Sabun dipotong sesuai dengan bentuk yang diinginkan dan disimpan selama 4 minggu. 


\section{Analisis dan Pengamatan}

Sabun katekin dievaluasi organoleptiknya yang meliputi warna, tekstur, bau dan aroma ( SNI, No 063532-1994), uji tinggi busa dan kadar air (SNI 3532:2016), pH dan uji iritasi (Mulyani, 2015).

\section{HASIL DAN PEMBAHASAN}

Pemeriksaan organoleptis dilakukan untuk mengetahui tampilan fisik dari sediaan yang meliputi bentuk, warna, dan bau. Hasil yang didapatkan adalah semua formulasi memiliki bentuk padat karena penambahan $\mathrm{NaOH}$. Perlakuan F1 dan F2 diperoleh warna cream, sementara F3 didapatkan warna coklat.

Busa merupakan salah satu cara untuk pengendalian mutu suatu produk sabun mandi agar sediaan memiliki kemampuan yang sesuai dalam menghasilkan busa. Namun tidak ada syarat dalam pengukuran tinggi busa minimum atau maksimum, karena tinggi busa tidak menunjukkan kemampuan dalam membersihkan. Hal berhubungan dengan nilai estetika dan kesukaan konsumen yang menyukai timbulnya busa berlebih. Uji tinggi busa masing-masing formula sabun padat katekin didapatkan tinggi busa, F1 (1.65.2), F2 (2.3-4), F3 (2.1-4).Banyak dari kita yang merasa kurang bersih jika sabun yang digunakan tidak mengeluarkan busa dan ketika sabun tersebut mengeluarkan banyak busa banyak dari kita yang merasa lebih bersih, padahal sebetulnya banyaknya busa sabun sebetulnya tidak berpengaruh dengan daya pembersihannya.

Hasil uji kadar air yang didapatkan pada penelitian sabun padat katekin untuk F1 mendapatkan nilai kadar air 14,94\%, F2 mendapatkan nilai kadar air 12,82\%, F3 mendapatkan nilai kadar air 14,6\%, ini telah memenuhi standar mutu sabun padat yaitu maksimal 15\% (SNI, 2016). Banyaknya air yang ditambahkan pada sabun akan berpengaruh terhadap kelarutan sabun. Semakin banyak air yang terkandung dalam sabun maka sabun akan semakin mudah menyusut pada saat digunakan.

Wasitaatmadja (1997) menjelaskan bahwa $\mathrm{pH}$ merupakan parameter yang sangat penting dalam suatu produk kosmetika karena $\mathrm{pH}$ kosmetik yang dipakai mempengaruhi daya absorbsi kulit.Pengujian $\mathrm{pH}$ yang telah dilakukan pada sabun padat katekin mendapatkan nilai pH F1 (9), F2 (10), F3 (9).Menurut standar, pH untuk sabun mandi berkisar antara 9-11 (Hernani dkk, 2010).

Hasil uji iritasi yang dilakukan terhadap panelis selama 24 jam, tiap formula menunjukkan tidak ada reaksi iritasi meliputi reaksi gatal-gatal, memerah, dan peradangan yang terjadi, uji ini dilakukan dengan cara uji tempel terbuka. Dan sifat iritasi sabun tidak bergantung pada $\mathrm{pH}$ sabun tetapi pada lamanya sabun berada dikulit setelah dibilas dan bagaimana absorbsi kulit terhadap sabun (Wasitaatmadja, 1997). Karna tidak adanya iritasi pada kulit, maka dianjurkan pada peneliti selanjutnya untuk menganalisa pengaruh penggunaannya pada kulit wajah yang berjerawat.

\section{SIMPULAN}

Berdasarkan penelitian didapatkan kesimpulan bahwa katekin dapat diformulasikan menjadi sediaan sabun padat dan telah memenuhi persyaratan evaluasi fisik yakni, uji organoleptis, uji tinggi busa, uji kadar air $(<15 \%)$, uji $\mathrm{pH}(9-10)$ dan uji iritasi.

\section{UCAPAN TERIMA KASIH}

Ucapan terima kasih disampaikan kepada pihak pihak yang telah ikut berperan dalam terlaksananya riset ini, yaitu : Bapak Ketua Yayasan Imam Bonjol Padang, Bapak Direktur Akfar Imam Bonjol dan mahasiswa (Itrianis, Desri, dan Ayulia).

\section{REFERENSI}

Aditya, M., Putri, RA., 2016. Manfaat gambir (Uncaria gambir Roxb) sebagai antioksidan, Majority, Vol 5:3.

Anggraini, T., Tai, A., Yoshino, T.,Itani, T., 2011. Antioxidative activity and catechin content of four kinds of Uncaria gambir extracts from West Sumatra, Indonesia, African Journal of Biochemistry Research Vol. 5(1), pp. 33-38.

BSN, 1994. Standar Nasional Indonesia SNI 06-3532-1994,Standar mutu sabun mandi. Badan Standarisasi Nasional

Hernani., Bunasor, T.K ., Fitriati., 2010. Formula sabun transparan anti jamur dengan bahan aktif ekstrak lengkuas (Alpinia galanga L.Swartz.), Bul Litro, vol 21(2),192-205.

Kemenperin., 2018. Industri kosmetik nasional tumbuh 20\% https://kemenperin.go.id/ artikel/18957/IndustriKosmetik-Nasional-Tumbuh-2018 
Kementan dirjen perkebunan., 2019. Ekspor gambir makin jadi primadona, http://ditjenbun.pertanian.go.id/ekspor-gambir-makin-jadi-primadona/.

Rabani, L., 2019. Karakteristik mutu sabun kopi dengan variasi waktu pencampuran dan waktu framming. AGRITEPA, Vol. V, No.2 DOI: https://doi.org/ 10.37676/agritepa.v6i1.810

Mulyani, D., Febriyenti., Almahdy., 2015. Pengaruh pemberian gel ekstrak belut (Monopterus albus) terhadap kecepatan penyembuh luka bakar tikus putih jantan Sprague-Dawley. Jurnal Sains Farmasi \& Klinis 2(2), 191-194

Neswati., Ismanto, S.D., Derosya. V., 2019. Analisis kimia dan sifat antibakteri sabun transparan berbasis minyak kelapa sawit dengan penambahan ekstrak mikropartikel gambir.Jurnal Agroindustri Halal 5(2): $171-179$.

Rahmawati, N., Bakhtiar, A., Putra, D.P., 2012. Isolasi katekin dari gambir (Uncaria gambir (Hunter). Roxb) untuk sediaan farmasi dan kosmetik.Jurnal Penelitian Farmasi Indonesia 1(1)6-10 ISSN 2302-187X.

Setyowati, H., 2017. Gambir (Uncaria gambir Roxb) as natural cosmeceutical agent.Department of Research and Development, Borobudur Natural Industry, Semarang, Indonesia.

Wasitaatmadja, S.M., 1997. Penuntun ilmu kosmetik medik.UI-Press; 1997. 3-5, 26, 124

Yeni, G., Silfia, S., Diza, Y.H., 2019.Pengaruh jenis pelarut dan kecepatan homogenizer terhadap karakteristik partikel katekin gambir.Jurnal Litbang Industri - Vol. 9 No. 1 